\title{
Diferenças na concordância verbal na narrativa de crianças de níveis socioculturais distintos ${ }^{1}$
}

\section{Differences in verbal agreement in written narrative by children from different socio- cultural levels}

Lidiomar José Mascarello*

Universidade Federal de Santa Catarina

Florianópolis - Santa Catarina /Brasil

RESUMO: O principal objetivo deste artigo é verificar se há diferenças significativas entre concordância e não concordância no uso do sistema verbal na narrativa escrita de crianças que vivem em ambientes socioculturais distintos. Foram pesquisados dois grupos com 52 alunos, em duas instituiçóes de ensino, uma privada e outra pública. Foram analisadas 1.190 sentenças, 595 de cada grupo, retiradas das narrativas escritas pelos alunos. A partir dos resultados obtidos na análise quantitativa e qualitativa, verificamos que existem diferenças significativas determinadas pelo aspecto socioeconômico cultural, mas que, na escrita dos alunos, a variação da concordância verbal não é muito diferente entre os dois grupos.

PALAVRAS-CHAVE: narrativa, níveis socioculturais, produção escrita, variedades sociolinguísticas.

ABSTRACT: The main objectives of this paper is to verify if there are differences between verbal agreement and non-agreement during the use of verbal system in written narrative by children who live in different sociocultural environments. In order to accomplish our objective, the students were divided in two groups of 52 children, one of them belonging to a public school and the other to a private one. Each group wrote narratives and this research analyzed 1190 sentences extracted from that narratives ( 595 of each group). From the results obtained with quantitative and qualitative analysis, we verified that there are meaningful differences related to sociocultural aspects but there was not a great variation in verbal agreement on the writing production of the two groups.

KEYWORDS: narrative, sociocultural levels, written production, sociolinguistics varieties.

${ }^{1}$ Artigo resultante de pesquisa de mestrado. Orientadora: Dra. Leonor Scliar Cabral. * lidiomarjose@gmail.com. Doutorando em Linguística pela Universidade Federal de Santa Catarina (UFSC), tutor em EAD na mesma universidade, professor do Colégio Santa Terezinha. 


\section{Introdução}

Pesquisas em Psicologia e Psicopedagogia tratando de interação social e aprendizagem mostram que a interação do ser humano com o ambiente e com os demais indivíduos é singular, e que cada indivíduo vivencia essas interações de forma peculiar e, ao mesmo tempo, complexa. A linguagem verbal é uma amostra da complexidade e capacidade de interação, distinguindo-se das demais formas de comunicação por apresentar características próprias e distintivas. Segundo Scliar-Cabral (2003, p. 29-40), a linguagem verbal oral ou escrita é caracterizada pela arbitrariedade, pela linearidade, pela retificação, pela capacidade de possibilitar a reflexão consciente (metalinguagem), por ser um sistema que permite a transmissão cultural, por ter função expressiva e estética, pela criatividade ou produtividade e pela retroalimentação total. Além dessas semelhanças entre linguagem verbal oral e linguagem verbal escrita, segundo a mesma pesquisadora, existem também algumas descontinuidades entre essas duas modalidades, contrastadas aos pares: por exemplo, determinantes bi psíquicos/determinantes culturais, aquisição da língua verbal oral e aprendizagem da escrita, coarticulação entre os sons/contraste entre as unidades gráficas, o estado de maior inércia da escrita comparado às mudanças mais rápidas da oralidade (SCLIAR-CABRAL, 2003, p. 40-48). Finalmente, a escrita é caracterizada pela ruptura espaço-temporal. A pesquisa realizada direcionou o olhar principalmente para a análise de algumas características do uso escrito da linguagem verbal em textos narrativos de crianças do Ensino Fundamental de níveis socioculturais distintos, considerando que os sujeitos pesquisados já obtiveram um bom desenvolvimento da linguagem verbal oral e dominam a sua variedade linguística, e estão elaborando o processo de aprendizagem da língua escrita possuindo algum domínio dela.

\section{Aprendendo a usar verbos}

Segundo Pinker (2008, p.40-41), a linguagem verbal é constituída por um conjunto de microcosmos, isto é, são muitas as características que precisam ser levadas em conta ao tentar defini-la, e, o sistema verbal constitui um microcosmo que funciona, de certa forma, como um quebra-cabeça: é preciso saber o lugar exato de cada peça para não ter problemas na montagem e no resultado final. Esse microcosmo se constitui do significado dos verbos, das possibilidades de cada verbo ser utilizado em sentenças e de como as crianças são capazes de decifrá-los. Para solucionar o problema da montagem do 
quebra-cabeça, Pinker afirma que "devemos estar atentos a todos os conteúdos que envolvem a cognição" (PINKER, 2008, p. 41); portanto, não são pontos isolados que proporcionarão as melhores respostas.

Ainda de acordo com Pinker,

[...] a mente humana é capaz de interpretar um cenário específico de diversas formas e cada interpretação é constituída em torno de algumas idéias básicas, como "fato", "causa", "mudança" e intenção. Essas ideias podem ser metaforicamente estendidas para outros domínios, como quando contamos os fatos como se eles fossem objetos ou quando usamos o espaço como metáfora para o tempo (PINKER, 2008, p. 41).

A mente humana é dotada de capacidade para solucionar problemas das mais diversas magnitudes, desde coisas rotineiras, como ver, ouvir, lembrar, falar (quando não há disfunções), dentre outras atividades cotidianas, até os sofisticados sistemas de engenharia. No entanto, segundo Pinker, "a compreensão do funcionamento dessas faculdades mentais é uma fronteira para a ciência moderna" (PINKER, 2008, p. 43). Dentre as faculdades mentais, destaca-se a linguagem, que vem recebendo um lugar especial nos estudos das ciências, principalmente da Neurociência e da Neurolinguística.

A linguagem ocupa a parte central nas relações interpessoais e se manifesta de inúmeras formas, o que por si já é surpreendente; mas mais surpreendente é a forma como se aprende a linguagem:

Os bebês nascem sem saber uma palavra da língua que se está falando a sua volta. E, em apenas três anos, sem benefício de aulas, a maioria está tagarelando, com um vocabulário de milhares de palavras, domínio da gramática do vernáculo oral e proficiência com o padrão de som (PINKER, 2008, p. 43).

As crianças se utilizam da língua e são capazes de utilizar os códigos com bastante segurança, sem se sentirem intimidadas, e demonstram compreender coisas que à primeira vista não fazem o menor sentido. E, para ser capaz de fazer isso, a criança precisa ter feito uma boa análise do discurso dos adultos, e não apenas ter decorado ou tentado memorizar o que eles falam. A criança aprende algumas regras e as utiliza, primeiro fazendo algumas generalizaçôes, o que pode provocar estranhamento aos ouvidos dos adultos.

É bastante surpreendente perceber que uma criança, ao fazer essas generalizações, não está apenas tentando se comunicar: ela está, segundo Pinker, resolvendo um problema de indução: "observar uma amostra limitada de fatos 
e estruturar uma generalização que englobe o conjunto infinito de onde os fatos são tirados" (PINKER, 2008, p. 44). As crianças, como qualquer ser humano, não conseguem simplesmente arquivar todas as frases que ouvem e tentar se utilizar posteriormente dessa memória como uma lista a ser consultada, assim como não é possível arquivar todas as palavras que diariamente são descobertas.

Para que haja êxito na comunicação, a criança deve ser capaz de "extrair um conjunto de regras que lhe permitirá compreender e expressar novos pensamentos e fazê-lo de uma maneira coerente com os padrôes de discurso utilizados pelas pessoas em sua volta" (PINKER, 2008, p. 45).

Entende-se, portanto, que a linguagem seja, de certa forma, um sistema integrado, único, mas constituído por vários componentes, e que, para entender o processo de aprendizagem da criança, é útil separar esses componentes. Pinker defende que cada um desses componentes se relaciona com sistemas cerebrais que "comandam a boca, o ouvido, a memória da pessoa para palavras e conceitos, os planos sobre o que dizer e os recursos mentais para atualizar o conhecimento com apreensão do discurso" (PINKER, 2008, p. 46).

Para Scliar-Cabral (2002), a aquisição da morfologia verbal é fundamental para a aquisição da gramática de qualquer língua. MacWhiney (apud SCLIARCABRAL, 2002) "evidenciou que a aprendizagem inicial da morfologia verbal envolve itens rotineiros ou amálgamas”. Já Tomasello (1992), também citado pela mesma pesquisadora, propôs a hipótese da "Ilha Verbal", isto é, cada verbo é marcado individualmente "(formas flexionais congeladas)".

O que se percebe é que os verbos são ricos em possibilidades, e ao mesmo tempo ricos em particularidades. As conjugações e as flexões são organizadas em paradigmas, nos quais cada verbo normalmente tem uma única forma primitiva, mas existem os verbos irregulares, que, segundo Pinker, “assumem uma posição na matriz mental" (PINKER, 2008, p. 59), e no início do processo de aquisição as crianças não conseguem perceber algumas formas agramaticais que essas exceções podem gerar, pois suas construções verbais, diferentes das conjugações, não se organizam em compartimentos regulares.

Ao dar-se conta das diferenças estruturais, a criança vai descobrindo novas possibilidades na língua, estabelecendo novas regras e novas generalizaçôes. Esse processo de descobertas acontece de forma natural na aquisição da linguagem verbal oral, e o tempo para cada criança realizar esse processo, ainda que seja muito semelhante, pode ter variações, mas na aprendizagem da escrita precisa ser sistematizado e ensinado (principalmente porque normalmente a variedade linguística aprendida na escola não é a mesma da utilizada em casa, 
realidade comum nas escolas brasileiras), e uma das dificuldades básicas decorrentes é que a criança tende a reproduzir na escrita aquilo que ela fala, acarretando algumas dificuldades, uma vez que nem tudo o que é licenciado na fala é licenciado na escrita da mesma forma e em todas as circunstâncias. Inicia-se aí um novo processo de aprendizagem sobre a língua, que é o da aprendizagem da leitura e da escrita. Nesse momento, a narrativa pode fazer a diferença, pois ela já está presente na vida dos sujeitos.

\section{A narrativa escrita, um meio para mostrar conhecimentos}

O conceito mais básico nos diz que, para que se constitua uma narrativa, é necessário que existam o narrador, os personagens, o espaço, o tempo e o enredo; portanto, toma-se como princípio que as narrativas sejam mediadoras, e não fins em si mesmas. Por isso, ao serem inseridas em um contexto de ensino de língua materna, não parecem categorias isoladas ou destituídas de cotidianidade, ainda que seja possível categorizá-las de diversas formas, por exemplo: narrativas literárias, ficcionais e factuais não situadas. Ao longo da nossa vida, vivemos em meio a muitas narrativas. Desde muito cedo, ouvimos histórias de nossas famílias, de como era a cidade ou o bairro há muito tempo; como eram nossos parentes quando mais novos, como éramos quando bebês, e assim por diante. Ouvimos também histórias de medos, de personagens fantásticos, de sonhos. Enfim, ouvimos, contamos, lemos, assistimos a, imaginamos histórias. A narrativa permite a ativação de processos como criação de cenários, estruturação de espaços mentais, mesclagem conceptual, ${ }^{2}$ capacidade de percepção, de categorização e de abstração; em outras palavras, é um recurso linguístico que tenta reviver eventos ocorridos ou imaginados. Muitas vezes, o limite real/fictício é indefinível, mas tanto narrativas factuais quanto ficcionais se fazem presentes em todas as populações, tanto na modalidade oral quanto na escrita. Nas populações ágrafas, apenas na modalidade oral:

[...] as narrativas orais encontradas em muitas populações ágrafas não resultam do efeito reversivo dos textos escritos e sim do fato de a memória humana ser programada para registrar os episódios vividos

\footnotetext{
2 Os espaços mentais são constructos teóricos projetados para modelar e indicar organização cognitiva de alto nível (FAUCONNIER, 1994, p. 31). E a mesclagem conceptual, para a Linguística Cognitiva, é uma operação cognitiva que envolve projeção de elementos selecionados de, no mínimo, dois espaços de input, resultando em integração conceptual (AZEVEDO, 2006, p. 37).
} 
e ou transmitidos pela coletividade oralmente (SCLIAR-CABRAL, 2003, p. 26).

Como veículo para transmissão cultural, a narrativa de "modalidade escrita tem caráter mais permanente, por isso mais eficiente que a modalidade oral nesse quesito" (SCLIAR-CABRAL, 2003, p. 33).

Pesquisas demonstram que, quando começam a frequentar a escola, as crianças já desenvolveram esquemas que lhes permitem compreender e produzir histórias que influem na memorização dos acontecimentos relatados e na complementação que elas fazem de relatos. ${ }^{3}$ Muitos autores chegam a afirmar que a organização narrativa é a "metáfora orientadora" (GERGEM; GERGEM, 1986 apud LANDSMANN, 1998), isto é, as narrativas são responsáveis para que a orientação do aprendizado seja estruturada em uma instituição ou mais livre no cotidiano, e através delas os fenômenos podem ser compreendidos, em quase todas as idades e culturas. A narrativa se tornou um objeto privilegiado para compreender os processos organizacionais da sociedade, a formação da psique, a constituição de valores culturais e suas transições.

Segundo Barthes, a narrativa contempla uma vasta diversidade de ocorrências da vida humana:

Inumeráveis são as narrativas do mundo. Há em primeiro lugar uma variedade prodigiosa de gêneros distribuídos entre substâncias diferentes como se toda matéria fosse boa para que o homem lhe confiasse suas narrativas: a narrativa pode ser sustentada pela linguagem articulada, oral ou escrita, pela imagem fixa ou móvel, pelo gesto ou pela mistura ordenada de todas estas substâncias; está presente no mito, na lenda, na fábula, no conto, na novela, na epopéia, na história, na tragédia, no drama, na comédia, na pantomima, na pintura, no vitral, no cinema, nas histórias em quadrinhos, no fait divers, na conversação. Além disto, sob estas formas quase infinitas, a narrativa está presente em todos os tempos, em todos os lugares, em todas as sociedades; a narrativa começa com a própria história da humanidade; não há em parte alguma povo algum sem narrativa; todas as classes, todos os grupos tem suas narrativas (apud GONÇALVES; FRITZEN, 2008, p. 2-3). ${ }^{4}$

${ }^{3}$ Ver por exemplo, Mandler (1979); Mandler; Scribner; Cole; Deforest (1980); Mandler; Stein; Trabasso (1984) (apud LANDSMANN, 1998), Scliar-Cabral (1982; 1983; 1984). ${ }^{4}<$ http://www.historiaimagem.com.br/edicao6abril2008/08-narrat-manga-fritzengoncalves.pdf>. 
A capacidade de narrar está integrada num conjunto de habilidades desenvolvidas pelas crianças durante o processo de aquisição da linguagem que as acompanha por toda vida, pois a narrativa indica a capacidade de produzir textos e supóe conhecimentos de regras culturais e sociais do grupo a que a criança pertence e que são acionadas no momento da comunicação. "Para participar efetivamente de interaçôes verbais a criança precisa entender que a comunicação não se faz através de palavras e frases isoladas" (SOARES, 1999, p. 227). A participação na comunicação se dá de forma mais significativa e completa quando a criança compreende e consegue configurar estruturas denominadas textos, ou seja, quando os objetos discursivos são vinculados a um universo de referência. Para que isso ocorra, é necessário que o sujeito desenvolva uma capacidade de uso da linguagem que envolva o alargamento da competência textual e a capacidade de elaborar estratégias e planejamento, envolvendo também habilidades cognitivas e metacognitivas para executar esses planos. Isso ocorre antes no plano da oralidade que no da escrita.

\section{Materiais e métodos}

Para realizar esta pesquisa, iniciou-se, no final de 2008, uma proposta de estudo sobre concordância verbal em narrativas de crianças em processo de alfabetização que vivem em contextos socioculturais distintos. A partir daí, buscou-se a viabilidade de desenvolvimento da mesma, tendo como primeiro passo a aprovação do projeto junto ao Comitê de Ética e junto à Secretaria Municipal de Ensino, uma vez que a pesquisa envolveria um estabelecimento público de ensino. Ao mesmo tempo, iniciaram-se a procura e os contatos com os estabelecimentos de ensino público dos bairros de Florianópolis. A partir da aceitação, foram realizadas várias reuniōes com a direção das escolas, bem como com a coordenação pedagógica e a secretaria (no estabelecimento de ensino público; na instituição privada, tudo foi tratado com a direção e a coordenação pedagógica) para a preparação e elaboração do material necessário para a comunicação aos pais e aos alunos.

Antes de aplicar os testes para a coleta de dados, foi realizada uma pesquisa piloto a fim de testar os instrumentos de pesquisa. Após vários contatos com os alunos, foi entregue um questionário sociocultural para a coleta de dados informativos para a identificação de algumas características específicas de cada família; esses questionários foram recolhidos no dia da realização do exercício e do teste, e, finalmente, em um novo contato, foram aplicados o exercício e o teste. 
Na aplicação do teste, seguiram-se os seguintes passos:

- Aplicação do exercício com parte da história de Chapeuzinho Vermelho (pequeno diálogo);

- Conferência do exercício feito para verificar se todos conseguiriam realizar o teste;

- Aplicação do teste.

Os comandos dados na aplicação foram: "vocês vão receber uma história, eu vou ler o início e a cada balãozinho que aparecer na sequência vocês vão ter tempo para escrever as falas dos personagens como se fossem os próprios personagens. Vamos ver se vocês entenderam bem, nós vamos primeiro fazer um exemplo com a história da Chapeuzinho Vermelho, como exercício treino.

[...] a Chapeuzinho Vermelho chegou à casa da vovó. Toc! Toc! Toc! (bateu na porta). A vovó (lobo) perguntou: (aqui os alunos completam a sentença)".

Realizados os passos 1 e 2, iniciou-se o 3 com o seguinte comando: "vocês estão recebendo as folhas com uma história que vocês não conhecem. Comecem a ler e coloquem nos balóes as falas dos personagens como eles dizem, se vocês não compreenderem alguma coisa levantem o braço para eu explicar. Prontos? Então podem começar".

Participaram do estudo 104 crianças de ambos os sexos, com idade entre 8 e 12 anos, que concluíram o terceiro ano do Ensino Fundamental, sendo 52 sujeitos de nível socioeconômico cultural (NSEC) baixo, estudantes de escola pública e residentes na periferia de Florianópolis, em São João do Rio Vermelho, e 52 sujeitos de NSEC alto, estudantes de escola privada e residentes na região central de Florianópolis. Como cada uma das duas escolas pesquisadas tinha mais de duas turmas de alunos que concluíram o terceiro ano e estavam iniciando o quarto ano, as turmas foram escolhidas a partir da disponibilidade e aceitação da professora regente e da disponibilidade dos alunos, e não seguiu nenhum critério classificatório. Não foram levadas em conta a metodologia e a atuação do professor (embora reconheçamos que sejam de fundamental importância na alfabetização). Na pesquisa, foram abordados aspectos linguísticos, retirados das sentenças das narrativas das crianças, e aspectos não linguísticos, indicados pelo questionário sociocultural aplicado. 


\section{Aspectos não linguísticos}

Em relação aos aspectos não linguísticos, consideramos aqui a profissão dos pais e a escolaridade, pois são os aspectos socioculturais que se mostraram mais significativos em relação às diferenças sociais dos grupos pesquisados.

Os nossos dados apontam certa diversificação na profissão dos pais dos alunos de NSEC alto, com destaque para a área do Direito e para o ramo de empresas. Ao todo, foram 47 respostas.

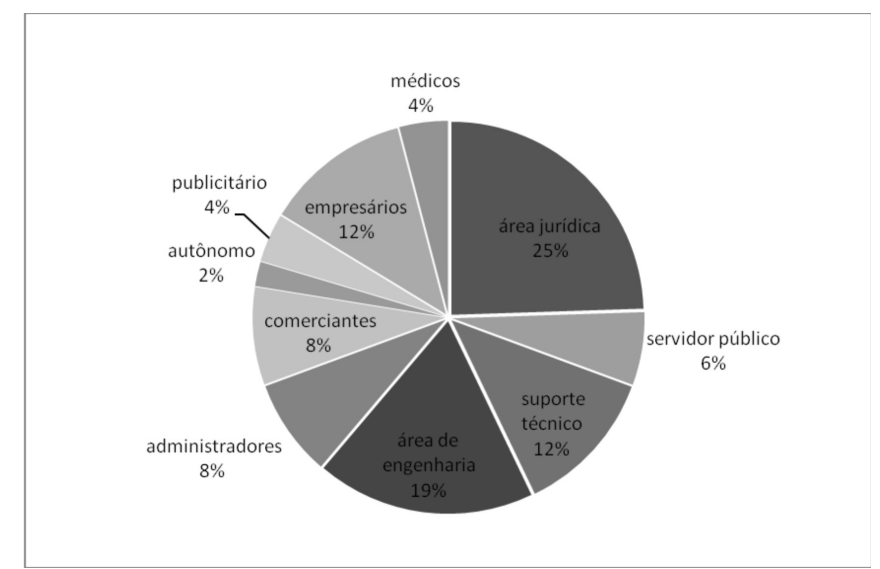

GRÁFICO 1 - Profissão dos pais dos alunos de NSEC alto

Em relação aos pais dos alunos classificados no NSEC baixo, observamos que as ocupações profissionais giram em torno de outra esfera. Aqui, o total de respostas foi 29:

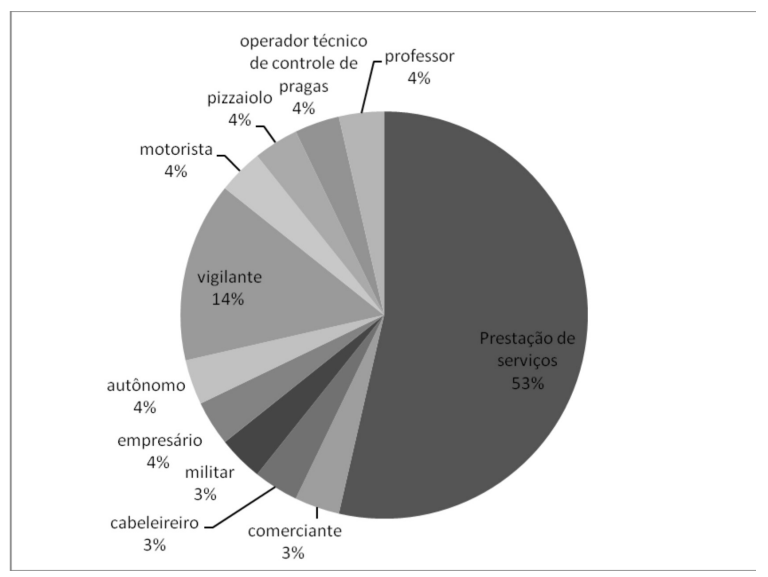

GRÁFICO 2 - Profissão dos pais dos alunos de NSEC baixo 
Se observarmos a profissão das mães, também constatamos diferenças significativas em relação aos dois grupos observados. Entre mães dos alunos de NSEC alto, como podemos observar no GRAF. 3, a maior percentagem é a ocupação em advocacia (16\%). No total, foram 45 respostas:

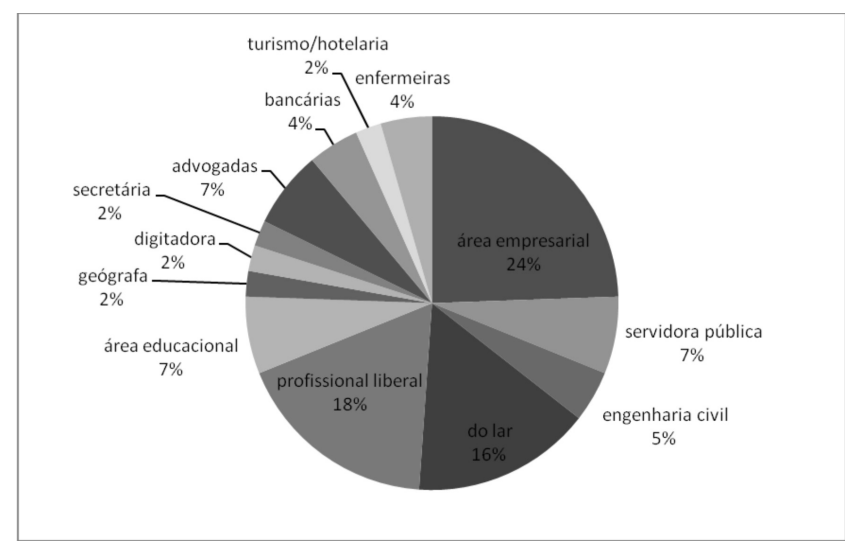

GRÁFICO 3 - Profissão das mães dos alunos de NSEC alto

Já a ocupação predominante entre as mães dos alunos do grupo NSEC baixo é a de prestação de serviços gerais (38\%). Foram 37 respostas.

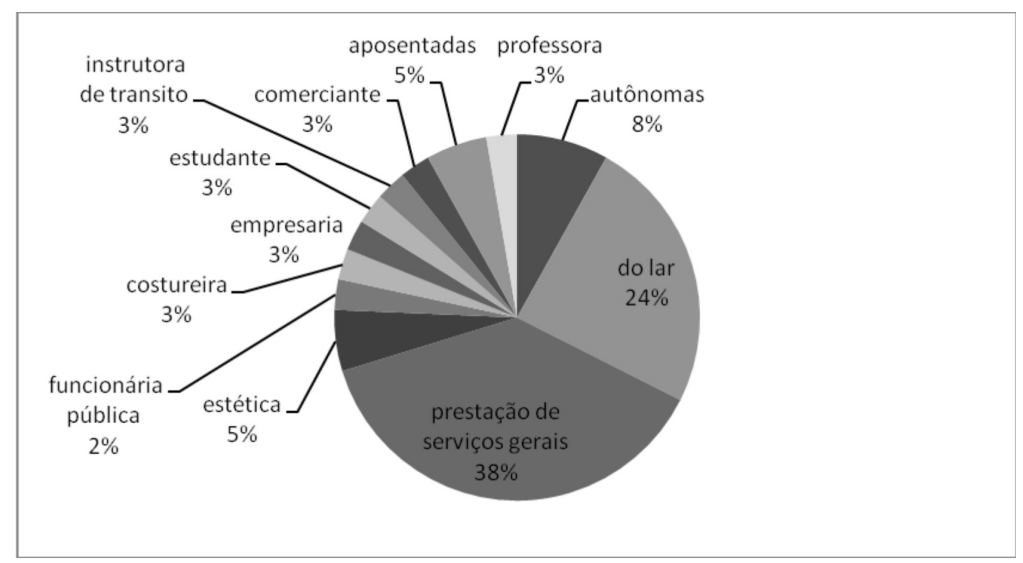

GRÁFICO 4 - Profissão das mães dos alunos de NSEC baixo

Outro aspecto relevante, e que foi considerado, é a escolaridade dos pais e mães dos estudantes. Veja-se, a seguir, os GRAF. 5 e 6 com as informações referentes ao NSEC alto: dos pais, foram 47 respostas, e das mães, 73. 


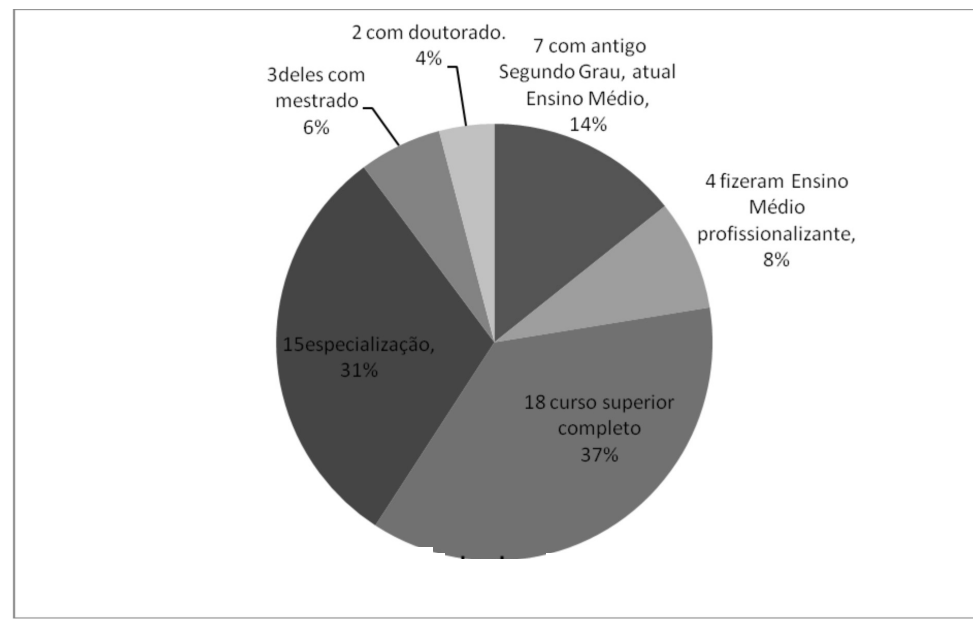

GRÁFICO 5 - Escolaridade dos pais dos alunos de NSEC alto

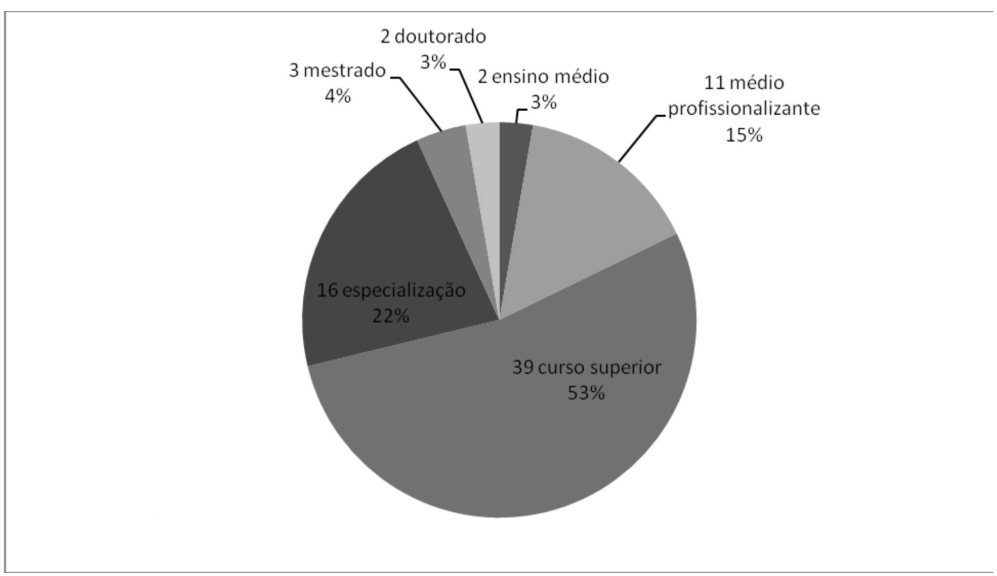

GRÁFICO 6: Escolaridade das mães dos alunos de NSEC alto

Como podemos constatar, a maioria dos pais e das mães dos alunos de NSEC alto tem formação superior, diferentemente do que podemos observar nos gráficos abaixo, referentes aos pais e mães dos alunos de NSEC baixo. Dos pais, foram 31 respostas, e das mães, 40 . 


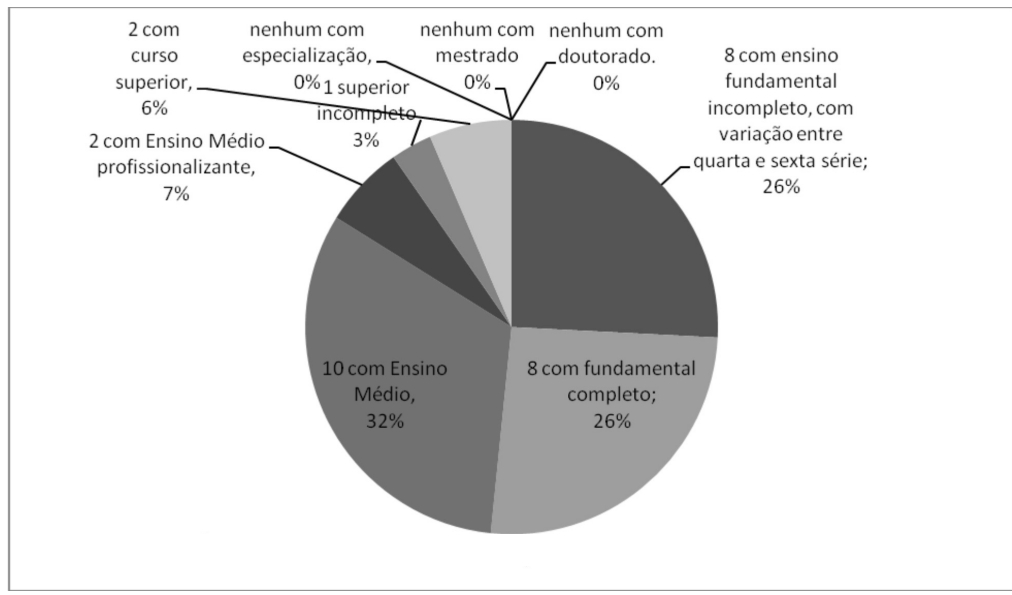

GRÁFICO 7: Escolaridade dos pais dos alunos de NSEC baixo

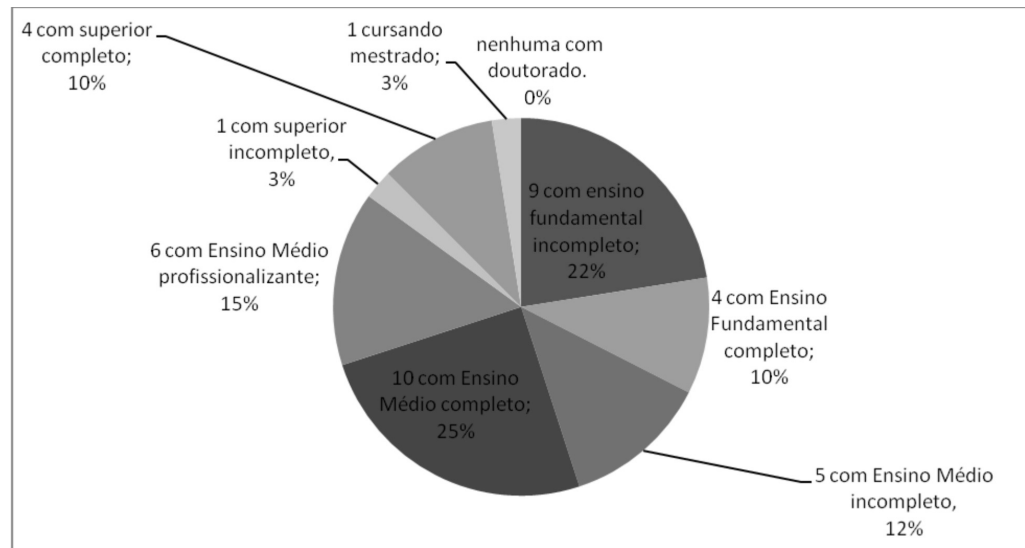

GRÁFICO 8: Escolaridade das mães dos alunos de NSEC baixo

A maioria dos pais tem apenas o Ensino Fundamental; o mesmo ocorre com as mães.

Foi perguntado, também, se as famílias têm o habito de viajar, tanto em território nacional quanto em território internacional. $\mathrm{Na}$ checagem dos dados, observamos que, das 53 respostas dadas pelas famílias de NSEC alto, no item "viagens nacionais", todos viajaram; já nas 30 respostas dadas pelas famílias dos alunos de NSEC baixo, 8 responderam que nunca viajaram.

No item "viagens internacionais", no grupo de NSEC alto, das 40 respostas, todos os pais informaram ter viajado para algum país diferente, e os filhos acompanharam os pais na maioria das viagens. Já no grupo de NSEC 
baixo, das 36 respostas dadas, 29 nunca fizeram uma viagem internacional, e os que viajaram não levaram os filhos.

Em relação à estrutura familiar, tanto o grupo de NSEC alto quanto o grupo de NSEC baixo se assemelham, e predomina a combinação pai/mãe/ irmãos. Constata-se, também, que a combinação mãe/outra pessoa é mais comum que a combinação pai/outra pessoa. No grupo de NSEC alto, das 48 respostas, 39 responderam que vivem com pai/mãe/irmãos, 2 só com o pai, 3 só com a mãe, e 4 com a mãe e outra pessoa. No NSEC baixo, das 30 respostas dadas, 21 indicam que vivem com pai/mãe/irmãos, 1 com o pai e outra pessoa, e 8 com a mãe e outra pessoa.

Ao tratar do acesso à informação e à tecnologia, constata-se uma diferença muito grande no que diz respeito ao acesso à internet: das 54 respostas dadas pelo grupo de NSEC alto, todos informaram ter acesso diário à internet em casa. Já das 36 respostas dadas pelo grupo de NSEC baixo, apenas 7 informaram ter acesso à internet em casa, e ainda assim com restriçóes (acesso por cerca de uma hora diária), e 29 não têm acesso à internet em casa.

Em relação ao acesso a livros: no grupo de NSEC alto, das 53 respostas, todos informaram ter acesso a livros, bem como a jornais e revistas, televisão e rádio.

Em contrapartida, no grupo de NSEC baixo, 4 dos 33 que responderam a questão sobre livros disponíveis em casa afirmaram não ter nenhum livro; 8 das 34 respostas referentes a acesso a revistas e jornais também dizem não possuir. Todos têm acesso a TV e rádio.

Quando perguntados sobre hábitos de leitura, das 50 respostas dadas pelos pais do grupo de NSEC alto, 31 leem diariamente, e 19 leem às vezes. Dentre as mães dos alunos desse mesmo grupo, das 47 respostas, 27 leem diariamente, e 20 às vezes.

Dentre os do grupo de NSEC baixo, ao serem abordados sobre a mesma questão, das 36 respostas dos pais, 8 afirmam ler diariamente, 10 às vezes, 9 raramente, e 9 nunca. Das 40 respostas dadas pelas mães, 15 afirmam ler diariamente, 14 às vezes, e 11 raramente.

Quando perguntados sobre espaço exclusivo dedicado à biblioteca, das 45 respostas dadas pelos alunos do grupo de NSEC alto, 25 informaram possuir biblioteca em casa, e 20 informaram não ter. Sobre o mesmo tema, no grupo de NSEC baixo, obtivemos 35 respostas: 10 afirmaram ter um espaço para biblioteca, e os demais não têm.

Ao observar todos esses dados, constatamos e confirmamos diferenças sociais e culturais importantes que de forma direta ou indireta interferem no 
processo de ensino/aprendizagem e na formação cultural dos indivíduos: os que têm acesso a um maior número de informaçôes e a uma maior troca cultural na interação têm maior possibilidade de melhorar o vocabulário e maior facilidade para expressar-se, seja de forma escrita ou oral: não é uma regra geral e absoluta, mas uma forte tendência.

\section{Análise e discussão dos dados das produções narrativas dos alunos}

$\mathrm{Na}$ análise das narrativas escritas dos alunos, consideramos como fatores não linguísticos a sua realidade socioeconômica cultural. Os fatores linguísticos observados foram: a posição do sujeito em relação ao verbo (se era anteposto ou posposto), o traço humano do sujeito [+ humano] e [- humano], ${ }^{5}$ a saliência [+ saliência] e [- saliência]. É importante ressalvar que no português brasileiro escrito e revisado não ocorre variação com sujeito simples plural: é bem difícil isso ocorrer. Essa variação pode ocorrer quando o núcleo do sujeito é plural. Via de regra, a concordância de número verbo/sujeito é regida pelo traço morfológico de número do núcleo do sujeito. Scherre e Naro (2005) apontam outras condiçôes, como o sintagma nominal encaixado, mas aqui elas não serão tratadas.

Para o tratamento quantitativo dos dados, utilizaram-se os programas computacionais conhecidos na literatura como GoldVarb, ${ }^{6}$ na sua versão 2001, e Excel 2007.

${ }^{5}$ Contrastando com o que realmente aconteceu no gênero factual, o que predomina no gênero conto de fadas é a função imaginativa no sentido definido por Halliday (1975, p. 20): “[...] a função da linguagem através da qual a criança, ela mesma, cria um ambiente". Em consequência, os contos de fadas usualmente começam com fórmulas mágicas do tipo "Era uma vez", as quais suspendem o tempo e o aspecto factuais em favor do tempo e espaço fictícios, bem como por uma entoação peculiar, marcada por chaves bem contrastantes.

Eles também terminam por fórmulas mágicas do tipo "E então viveram felizes para sempre”, quando os participantes retornam ao real. Esse mundo imaginário admite a violação de traços semânticos. Existem violações consistentes e extraordinárias dos traços semânticos mais altos, tais como [- animado] e [- humano], quando as pedras podem falar e a maioria das vezes os animais são personagens. Em consequência disso atribuímos valor de [+ humano] aos animais personagens.

${ }^{6} \mathrm{O}$ programa GoldVarb fornece como produto final pesos relativos associados aos diversos fatores dos grupos de fatores variáveis independentes considerados, bem como a seleção desses grupos em função de sua relevância estatística. Os valores indicam o efeito que cada um dos fatores tem sobre as variantes do fenômeno que foi analisado. 
Analisamos 1.190 (mil cento e noventa) sentenças, dados escritos. Consideramos 9 (nove) grupos de fatores para serem controlados:

(1) concordância e não concordância verbal, variável dependente;

(2) nível socioeconômico cultural;

(3) instituição de ensino;

(4) traço humano do sujeito;

(5) sujeito nulo e sujeito expresso/preenchido;

(6) posição do sujeito;

(7) saliência;

(8) pessoas gramaticais;

(9) erros grafêmicos que interferem na concordância.

Dizemos que há concordância quando o sujeito está concordando com o verbo, como em: "nós vamos passear pelo zoológico", 7 e dizemos que não há concordância quando o sujeito e o verbo não obedecem às mesmas regras, como em: "eu que ver os leões". Em relação a esse fator linguístico, obtivemos como resultados de concordância e não concordância em relação à variável "nível socioeconômico cultural" o que podemos observar no GRAF. 9:

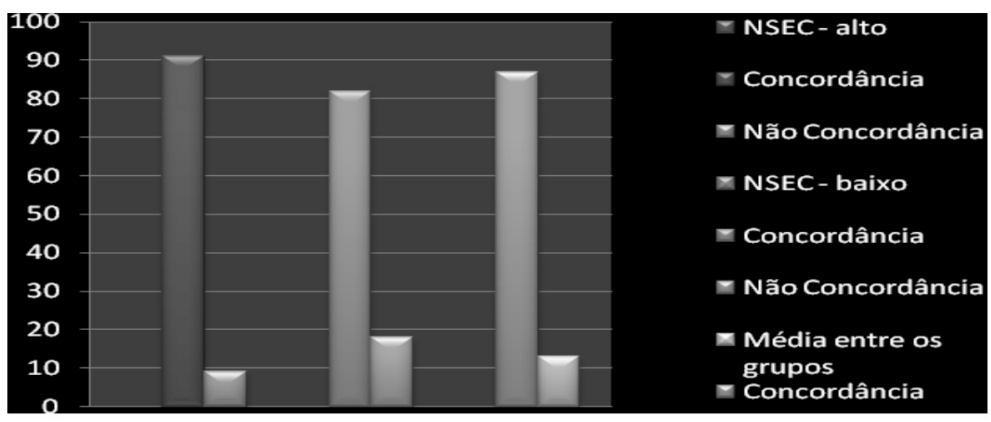

GRÁFICO 9 - Concordância verbal

Das 1.190 sentenças analisadas, constatou-se que há uma média de $87 \%$ de concordância e $13 \%$ de não concordância. Entretanto, se observarmos os grupos separadamente, constata-se que o grupo de NSEC alto apresenta 9\%

\footnotetext{
${ }^{7}$ As sentenças destacadas foram retiradas dos textos narrativos dos alunos. Muitas estão grafadas em desconformidade com a regra determinada pela norma padrão, e foram mantidas de acordo com o registro feito pelos estudantes.
} 
de não concordância, enquanto o grupo de NSEC baixo apresenta 18\% de não concordância.

Em relação ao tipo de instituição, escola privada e escola pública, os dados são os mesmos dos anteriores.

Conforme definido na nota 6 , o traço mais humano é o que se refere aos seres que adquirem aspecto de humanidade na narrativa, como em "você vai cair": você é o pronome de tratamento que indica condição humana. $\mathrm{O}$ traço menos humano é tudo o que se refere a outros seres ou eventos, como em "a estrada vai acabar no precipício": estrada é o nome que se refere a algo não humano.

Em relação a este fator (grupo 4), "traço humano do sujeito [+ humano] e [- humano]”, observam-se no GRAF. 10 os seguintes dados:

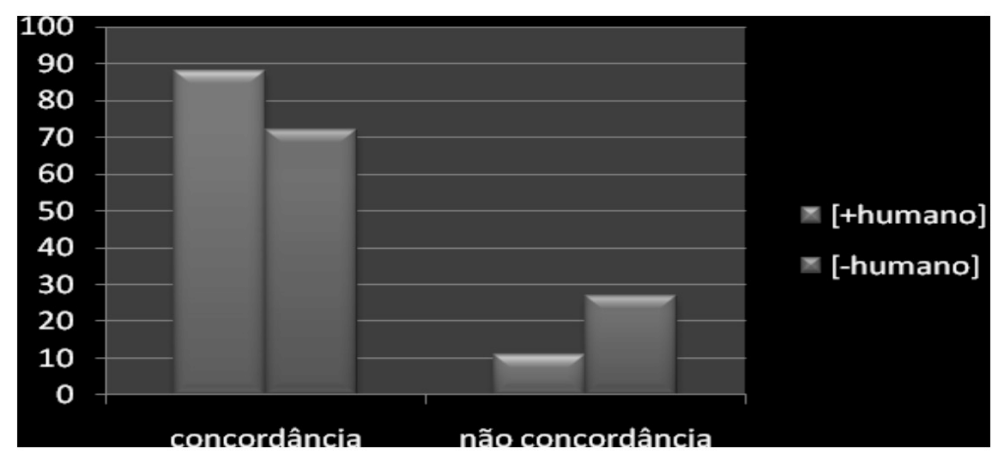

GRÁFICO 10 - Traço do sujeito [+humano]/[-humano]

Ao observar o traço humano do sujeito, constata-se que em $89 \%$ dos casos em que o sujeito apresenta o traço [+humano] ocorre concordância, diferenciando-se do traço [- humano], em que a concordância cai para $73 \%$. Esse dado segue a mesma direção dos estudos de Scherre e Naro (1998) e Naro e Scherre (2000). Os autores evidenciam que, se o sujeito plural for [humano], a presença de marca de plural no verbo é menos provável, e, se for [+ humano], o plural explícito é, relativamente, mais provável.

Consideramos como sujeito nulo a sentença em que não está explicitamente manifesto o sujeito, como em "vamos comesar a brincar", e como sujeito preenchido sentenças em que o sujeito aparece explicitamente, como em "eu quero ir ver as girafas".

Em relação a esse fator (grupo 5), "sujeito preenchido e sujeito nulo", obtivemos os seguintes resultados: 


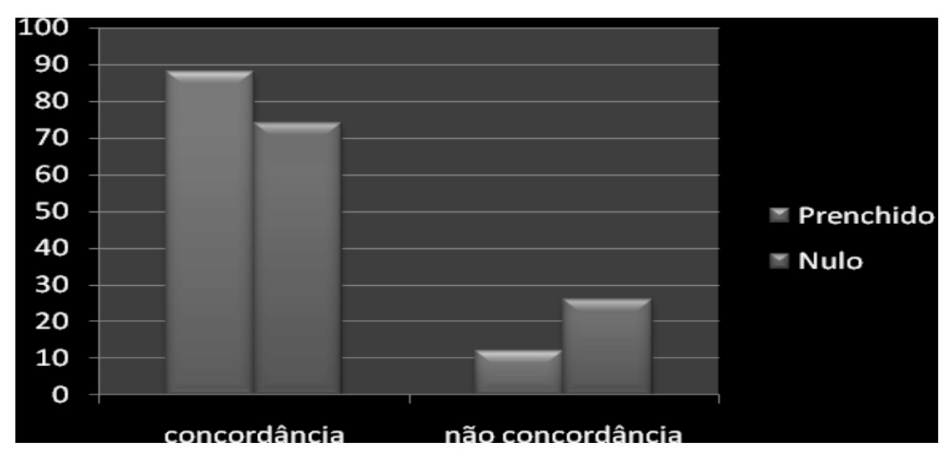

GRÁFICO 11 - Preenchimento do sujeito

Em 970 ocorrências com sujeito expresso, 88\% das ocorrências tiveram concordância, e 12\% não tiveram concordância. Em relação ao sujeito não expresso, $74 \%$ das ocorrências fizeram concordância, e 26\% não concordaram.

O fator posição do sujeito diz respeito ao local da sentença em que o sujeito está situado em relação ao verbo. Temos, portanto, anteposição em "você quase caiu no precipício", pois "você" está expresso antes do verbo "cair". Temos posposição do sujeito em "chegou visitas", pois "visitas" é o sujeito do verbo "chegar", e está expresso na sequência da sentença depois do verbo.

Em relação a este fator (grupo 6), "posições do sujeito", observam-se os seguintes resultados:

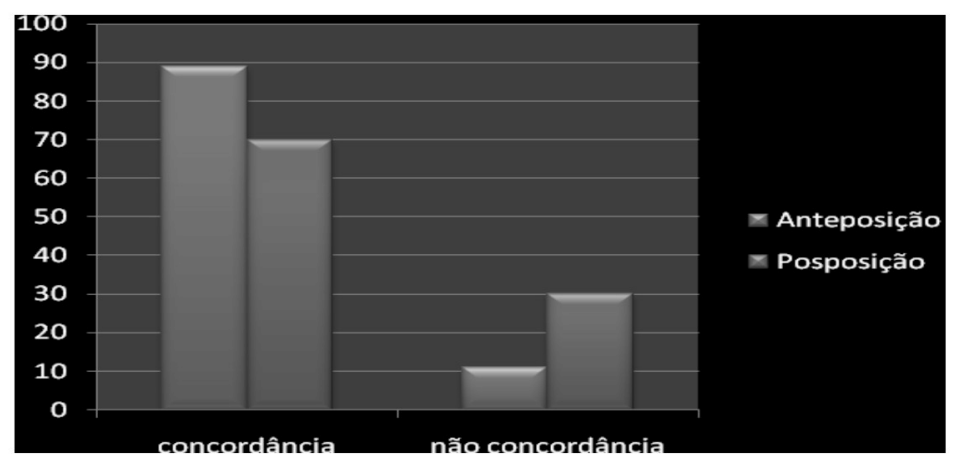

GRÁFICO 12 - Posição do sujeito

Observa-se que, quando o sujeito é anteposto, a probabilidade de concordância é maior: os dados apontam para $89 \%$ de concordância. Por outro lado, a concordância para $70 \%$ quando o sujeito está posposto ao verbo. Esses 
resultados reafirmam o que foi apontado por Lemle e Naro (1977), Lira (1986), Berlinck (1988) e Monguilhott (2001).

Consideramos aqui como saliência a desinência exclusiva de cada verbo para cada pessoa gramatical em cada tempo da conjugação verbal. Temos mais saliência, portanto, em "você vai cair", em que "vai" é exclusivo de terceira pessoa no presente do indicativo, e menos saliência em: "você estava tão alegre", pois "estava" tanto pode referir-se à primeira quanto à terceira pessoa do imperfeito do indicativo.

Quanto a esse fator (grupo 7), "saliência", os dados apontam os seguintes números:

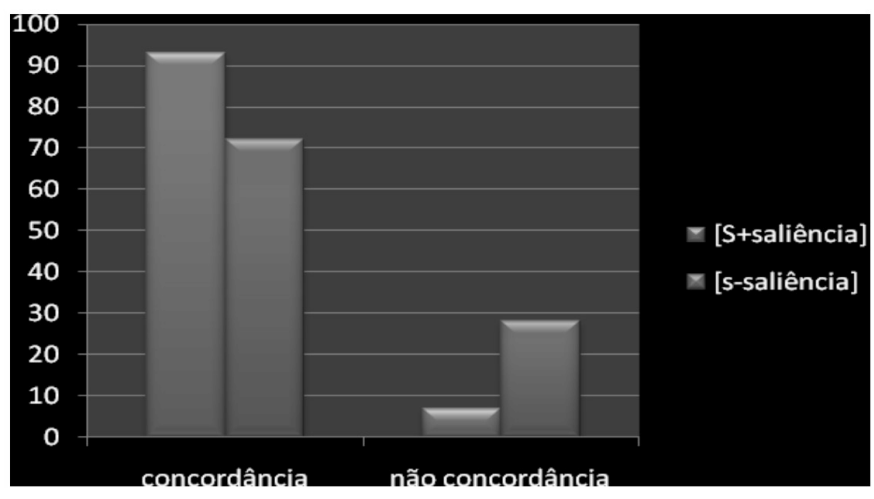

GRÁFICO 13 - Saliência

Observa-se que em 93\% das ocorrências em que aparece [+ saliência], ocorre concordância verbal, diferentemente dos $72 \%$ das ocorrências em que se vê a presença de traço [- saliência]. Os estudos de Naro (1981) já faziam alusão a esse traço linguístico, e afirmavam que a presença ou a ausência de acento na desinência e a quantidade de material fônico que diferencia a forma singular da forma plural interferem na concordância verbal. Os dados de Monguilhott (2001), ao pesquisar a variação de concordância verbal de terceira pessoa, também apontam para a mesma direção.

O fator pessoas gramaticais diz respeito às pessoas utilizadas como referências para organizar as sentenças; temos, por exemplo, p1 em "eu quero ir ver os elefantes", p2 em "Tu tás gorda em", p3 em "Deixa ele vim", p4 em "Nós vamos ver mais animais", e p6 em "eles estão presos". ${ }^{8}$ Para estabelecer a pessoa do discurso, estabelecemos como ponto de partida a terminação do verbo.

${ }^{8}$ Não foram encontrados registros de p5 nos dados. 

dados:

Quanto a este fator (grupo 8), "pessoas gramaticais”, têm-se os seguintes

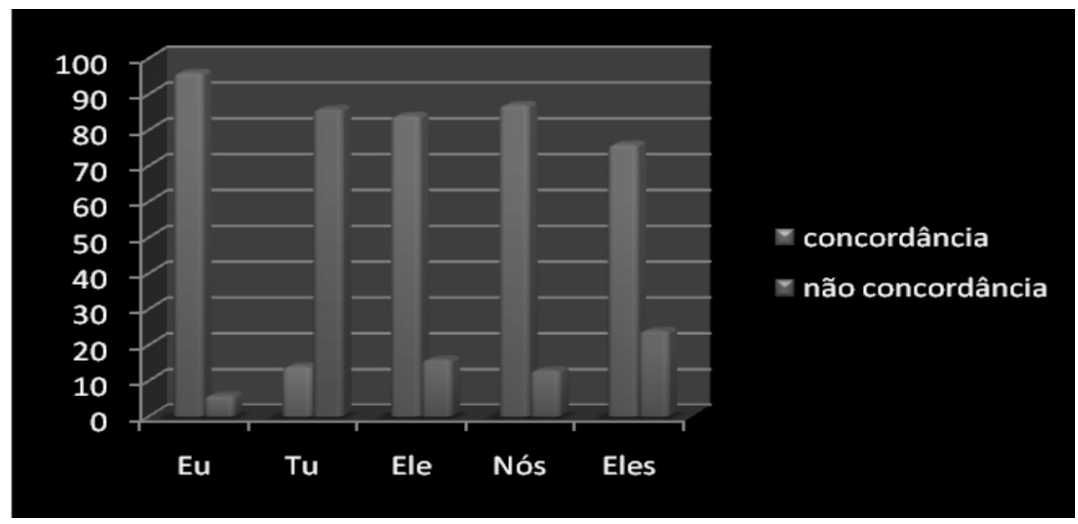

GRÁFICO 14 - Pessoas gramaticais

Ao observar os dados, constata-se que foram utilizadas 28 sentenças com "tu" na segunda pessoa, e, dessas, $86 \%$ foram utilizadas sem concordância. Outro dado mais discrepante é em relação à não marcação do sujeito: constatase $100 \%$ de uso com concordância, referentes à marca de infinitivo ou ao gerúndio. O uso da primeira pessoa "eu" apresenta $94 \%$ de uso com concordância, o uso da terceira pessoa "ele" apresenta $84 \%$ de concordância, o uso da primeira pessoa do plural "nós" apresenta $87 \%$ de concordância, o uso da terceira pessoa do plural "eles" apresenta $76 \%$ de concordância, e a segunda pessoa do plural não foi utilizada, confirmando o que muitos autores defendem: que o "vós" está em desuso no português brasileiro.

Em relação aos erros grafêmicos, podemos observar que são consequentes de diferentes causas e possuem diferentes naturezas. ${ }^{9}$ Estão grafadas incorretamente as seguintes sentenças: "Os bicho ento enrolado socoro", "uma pessoa que sipota co a gete", "eu vo coloca você no andado", "Eu estro adado legau", "Eu vo tenta pega ele", "Ele vai cai”. A grafia incorreta, principalmente dos verbos, aumenta a não concordância.

9 Consideramos, com a finalidade da padronização, a ausência de $r$ na forma infinitiva ("vo tenta pega"), a ausência de $s$ na indicação de plural em p4 ("nós vamo") e a ausência de am em p6 ("eles voltaro") como erro grafêmico e ausência de concordância, embora teorias variacionistas considerem o segundo e o terceiro casos com presença de concordância. 
Quanto a esse fator (grupo 9), "erros grafêmicos", observa-se:

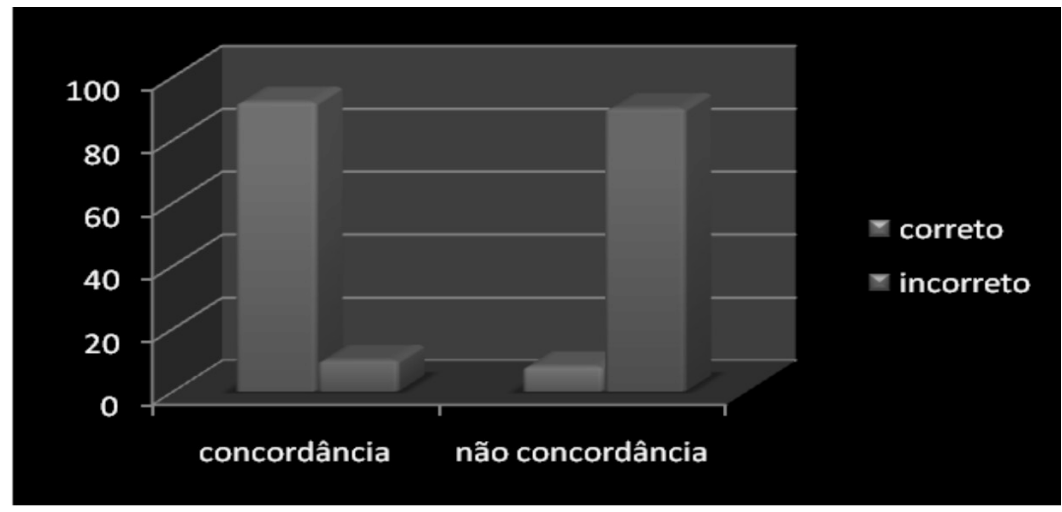

GRÁFICO 15 - Erros grafêmicos

Quando as sentenças são grafadas corretamente, obtêm-se 92\% de acertos na concordância, e quando ocorrem erros de grafia na marcação de pessoa e número ou modo temporal, ocorrem $90 \%$ de erros de concordância.

\section{Análise qualitativa dos dados}

Ao analisarmos os dados, um dos aspectos que nos chamou atenção foi a quantidade de erros grafêmicos cometidos pelas crianças. Podemos observar que $90 \%$ das sentenças que são grafadas incorretamente provocam erro de concordância; esses erros são variados e por vezes é difícil categorizá-los.

Muitos dos erros de concordância resultam da transcrição fonética imperfeita dos enunciados, como as crianças os percebem, sem aplicar as marcas grafêmicas que seriam necessárias. Outro fato corrente no português brasileiro é o uso do "você" como segunda pessoa do discurso, mas como terceira pessoa gramatical. O mesmo aparece constantemente nos textos das crianças. Tais erros acontecem em diferentes situações.

A marca do infinitivo, por exemplo, raramente é expressa, principalmente nos alunos provenientes de nível sociocultural mais baixo, o que pode ser interferência direta da fala dessa variedade, pois os diálogos no texto são representaçōes de fala dos personagens: ${ }^{10}$

\footnotetext{
${ }^{10} \mathrm{O}$ uso do infinitivo e do imperativo é questionado pela Sociolinguística quanto à possibilidade de ser considerado erro, principalmente nos diálogos narrativos que tendem a representar a fala dos personagens.
} 
293. eu vou bota o filhote aqui

363. [...] para brinca conosco

819. você ia cai do penhasco

930 eu vo coloca você no andado

933. ele vai cai

990. nossa que legal eu vou chama os meus amigos

Outra dificuldade que é possível constatar a partir dos dados é que as crianças são alfabetizadas pelos nomes das letras, e raramente é trabalhado o valor dos grafemas. É possível identificar fenômenos como:

964. pro que eu não to quo cede

1012. que ia quair no precipicio (o aluno aprendeu que depois do uso de qé necessário usar $u$, e então generaliza a regra. Ele também aprendeu o " $c$ " pelo seu nome, e não pelo valor $/ \mathrm{k} /$ antes de vogais [+ post].

Ao observar as sentenças abaixo, verifica-se o uso do infinitivo no auxiliar, enquanto o verbo principal deveria ir para o gerúndio:

601/602. Ele tar falavam que o macaco era um bicho esperto méis

607/608. Filho sabe que aquele menino tar oleto par voce

Não há concordância de tempos e modos nas oraçōes subordinadas, que, de acordo com a regra gramatical, deveriam ir para o subjuntivo.

Nas sentenças:

619. (eles) inta ficaro féis

620. eles vol(ta)ro para o zoligico

960. as girafa gostava de brinca muito

verificamos que há uma tentativa de transcrição fonética da variedade sociolinguística dos alunos, em que o verbo "ficar" no presente do indicativo muitas vezes é conjugado como eu fico, tu fica, ele fica, nois fica, eles fica, e no perfeito do indicativo: eu fiquei, tu ficô, ele ficô, nois fiquemo, eles ficaro (na última ocorrência, fic é o radical, $a$ é vogal temática, ra é indicação de modo temporal, em que /a/ é assinalada por $o$, indicação número pessoal [ $\mathrm{ra}+\mathrm{O}=\mathrm{ro}]$ ).

O mesmo ocorre com "as girafa gostava": temos uma frase iniciada com marcação de plural e o verbo conjugado no singular, pois nessa variedade sociolinguística temos eu gostava, ce(você) gostava, nós gostavo/gostava e eles gostava. 
Tal evento é um sinal claro de que algumas variedades sociolinguísticas discrepam mais da variedade padrão do português brasileiro do que outras, e isso implica maior empenho e sensibilidade do professor alfabetizador, ${ }^{11}$ ou seja, um trabalho com mais delicadeza e cuidado para evitar a exclusão do aluno que se utiliza dessa variedade para se comunicar oralmente, mas que precisa passar a utilizar, na comunicação escrita, a nova variedade que estão aprendendo.

Nas sentenças:

737. talvez eles põem nós no jornal, um que tal?

759. talvez nós poderíamos viajar

o uso de talvez indica dúvida, é dubitativo; por essa razão, exige que a concordância seja feita com o subjuntivo, e não com o presente do indicativo ou futuro do pretérito.

Em:

771. ai minha nossa, nos tamo na fossa

957. eu kiria vê a girafa

959. Eles tavo conversando cos amigo de eles

970. eles disseram i agora

1161. nós vamos axalo

temos, entre outros problemas de concordância, uma tentativa de escrita fonética dessa variedade sociolinguística. Em todo o corpus, percebe-se uma tentativa constante do uso da escrita fonética, o que indica que ainda existem dificuldades na escrita em consequência de uma alfabetização pouco eficiente. Ao ser alfabetizado pelo nome das letras, o aluno faz confusão em contextos de uso que exigem dele um maior conhecimento linguístico.

Outra construção comum e que independe do nível sociocultural é: 888. deixa ele vim

Ocorre, nesse caso, uma neutralização do infinitivo em favor da primeira pessoa do pretérito perfeito simples do indicativo.

São comuns também erros de concordância provocados pela não distinção entre o uso dos pronomes "tu" e "você", principalmente no modo

${ }^{11}$ Tudo isso depende também, em grande parte, da formação e da capacitação do professor. 
imperativo afirmativo: na maioria dos casos, usam "você" durante a escrita do texto e o verbo na segunda pessoa, confundindo com o presente do indicativo. Em virtude do uso cada vez mais difundido do "você" como segunda pessoa do discurso, embora seja a terceira pessoa gramatical, confundem-se cada vez mais os usos. Como no instrumento de elucidação propositadamente se usou uma história em quadrinhos em que os personagens dialogam, o fato foi muito observado:

\section{0. ola me dá um abraço}

635. olha a rua leão

638. olha o penhasco leoa

Em: “935. Você vio as pessoas?”, ocorre uma generalização da regra do grafema $o$ em final de vocábulo, representando /u/ átono, embora no exemplo trate-se do ditongo /iw/.

Em “958. Ele qui ria vê o leão", ocorre uma segmentação do verbo, e, ao realizar a segmentação, acaba com a unidade verbal e deixa de expressar o que realmente havia sido previsto.

Em "1088. eu se perdi", o aluno usa o verbo de forma correta, mas comete erro de concordância pronominal, o que revela mais um traço comum da sua variedade sociolinguística: eu se perdi, tu se perde, ele se perdeu, nos se perdemo, eles se perdero (não é nosso objeto de estudo, mas indica variação sociolinguística).

Verificamos com isso e, em primeiro lugar, comprovamos que realmente existem diferenças sociolinguísticas e que o grupo com nível sociocultural baixo se distancia mais da variedade padrão do português brasileiro, e, em segundo lugar, percebemos que esse mesmo grupo apresenta maiores problemas de alfabetização, muitos ainda não estão alfabetizados, indicando, assim, precariedade na alfabetização, pois ocorre pouco trabalho de metalinguagem com os alunos. Os dados indicam que as crianças precisam ser mais bem preparadas tanto na pré-escola quanto nos anos iniciais, e que a metodologia de alfabetização precisa ser modificada. É uma falácia insistir em que os alunos devam escrever como falam: isso pode ocorrer numa fase inicial do processo, mas o ensino/aprendizagem não pode se contentar com isso, sob pena de a escola estar produzindo um excluído do mercado de trabalho. 


\section{Considerações finais}

Ao concluir este estudo, verifica-se, a partir dos dados analisados, que as principais dificuldades das crianças em adequarem o sistema de flexão verbal na produção escrita ocorrem em função da alternância das pessoas do discurso e da forma de tratamento, principalmente na segunda pessoa do singular: ora utilizam "tu", ora "você", dificultando, inclusive, a análise, pois ora o verbo concorda com um, ora com outro dos pronomes. Outra dificuldade é com relação ao núcleo do sujeito singular e plural das sentenças. Essa era uma das preocupaçôes iniciais, e a outra era identificar se existem diferenças significativas entre produções escritas das crianças provenientes de NSEC baixo, estudantes de escola pública e residentes na periferia de Florianópolis, e crianças de NSEC alto, estudantes de escola privada e residentes na região central de Florianópolis. Em relação a essa segunda preocupação, os dados mostraram que a diferença no aspecto da concordância verbal entre os dois grupos é significativa. Em relação ao grupo de NSEC alto, os dados mostraram que ocorrem $91 \%$ de concordância, e em relação ao grupo de NSEC baixo, os dados indicam $82 \%$ de concordância, resultando em um percentual de 9 pontos de diferença entre os grupos. Esse resultado responde nossa questão: Qual dos dois grupos se aproxima mais da norma padrão da variante escrita do português do Brasil no que se refere à flexão verbal? E confirma a nossa hipótese: os morfemas flexionais de pessoa e número do sistema verbal na variedade sociolinguística de NSEC baixo e de escola pública discrepam mais da norma padrão escrita do português do Brasil que os da variedade sociolinguística de NSEC alto.

Além das preocupações iniciais e das hipóteses, os objetivos eram verificar se há diferenças significativas de concordância e não concordância no uso do sistema verbal na narrativa escrita de crianças que vivem em ambientes socioculturais distintos, bem como identificar como a narrativa pode favorecer o processo de aprendizagem de metalinguagem e como o contexto sociocultural interfere nesse processo de aprendizagem.

Os dados desta pesquisa apontam para diferenças socioeconômicas culturais bem significativas entre as famílias dos dois grupos (as quais são aspectos não linguísticos).

Em relação aos aspectos linguísticos, obteve-se uma diferença de variação significativa entre os dois grupos (NSEC alto x NSEC baixo).

Os dados linguísticos controlados, no entanto, vão na mesma direção de outras pesquisas realizadas, reforçando que, em relação ao traço, o [+ 
humano] favorece a concordância, e o traço [- humano] favorece a maior variação e a não concordância. A posição do sujeito antes do verbo também favorece a concordância, e a posição depois do verbo favorece a ocorrência de maior variação e a não concordância.

O mesmo ocorre com o grupo "saliência": quanto [+ saliência], menor a variação e maior a concordância, e quanto [- saliência], maior a variação e a não concordância.

Por fim, retomando Pinker (2008, p. 40), “a linguagem verbal é constituída por um conjunto de microcosmos, [...] e o sistema verbal constitui um microcosmo que funciona de certa forma como um quebra-cabeça”. Percebe-se que nem todas as crianças ainda conseguem colocar cada peça em seu devido lugar, por isso se faz necessário um processo de ensino/aprendizagem cuidadoso.

\section{Referências}

AZEVEDO, A. M. T. Estrutura narrativa e espaços mentais. Belo Horizonte: Faculdade de Letras da UFMG, 2006.

BERLINCK, R. A. A ordem VSN no português do Brasil: sincronia e diacronia. 1988. 265f. Dissertação (Mestrado) - Instituto de Estudos da Linguagem, Universidade Estadual de Campinas, Campinas, 1988.

FAUCONNIER, Gilles. Mental spaces: aspects of meaning construction in natural language. Cambridge, MA: Cambridge University Press, 1994.

GOLDVARB 2001. Um aplicativo de análise multivariada para Windows. Desenvolvido por John Robinson, Helen Lawrence e Sali Tagliamonte. 2001.

GONÇALVES, A. C.; FRITZEN, C. Narrativa autobiográfica e mangá: uma análise de Gen pés descalços. História, Imagem e Narrativas, ano 3, n. 6, p. 1-15, abr. 2008 Disponível em: <>. Acesso em: 3 dez. 2009.

HALLIDAY, M. A. K. As bases funcionais da linguagem. In: DASCAL, M. Fundamentos metodológicos da linguística. São Paulo: Global, 1973. p. 125-161. HALLIDAY, M. A. K. Learning how to mean: explorations in the development of language. London: Edward Arnold, 1975.

LANDSMANN, L. T. Aprendizagem da linguagem escrita, processos evolutivos e implicaçôes didáticas. 3. ed. São Paulo: Ática, 1998.

LEMLE, M. Heterogeneidade dialetal: um apelo à pesquisa. Revista Tempo Brasileiro, Rio de Janeiro, n. 53-54, 1978. 
LEMLE, M.; NARO, A. J. Competências básicas do português. Fundação Movimento Brasileiro (MOBRAL); Fundação FORD, 1977. Relatório.

LIRA, S. Subject postposition in Portuguese. D.E.L.T.A., v. 2, n. 1, p. 17-36, 1986.

MONGUILHOTT, I. O. S. Variação na concordância verbal na terceira pessoa do plural na fala de florianopolitanos. 2001. Dissertação (Mestrado em Linguística) - Instituto de Letras, Universidade Federal de Santa Catarina, Florianópolis, 2001. NARO, A. N. The social and structural dimensions of a syntactic change. Language, Cambridge: Cambridge University Press, v. 57, n. 1, 1981.

NARO, A. J.; LEMLE, Miriam. Syntatic diffusion. Ciência e Cultura, v. 29, n. 3, p. 259-268, 1977.

NARO, A. J.; SCHERRE, M. M. P. Variação e mudança linguística: fluxos e contrafluxos na comunidade de fala. Cadernos Estudos Linguísticos Campinas, n. 20, p. 9-16, jan./jun. 1991.

NARO, A. J.; SCHERRE, M. M. P. Contact with media and linguistic variation. In: ARNOLD, J. et al. (Ed.). Sociolinguistics variation: data, theory and analysis - selected papers from NWAV23 at Stanford. Stanford: Stanford University Press, 1996. p. 223-228.

NARO, A. J.; SCHERRE, M. M. P. Sobre o efeito do princípio da saliência na concordância verbal na fala moderna, na escrita antiga e na escrita moderna. In: MOURA, D. (Org.). Os múltiplos usos da língua. Maceió: EDUFAL, 1999a. p. 26-37.

NARO, A. J.; SCHERRE, M. M. P. A influência de variáveis escalares na concordância verbal. A cor das letras. Revista do Departamento de Letras e Artes da Universidade Estadual de Feira de Santana, Feira de Santana, n. 3, p. 17-34, dez. 1999b.

NARO, A. J.; SCHERRE, M. M. P. A hierarquização do controle da concordância no português moderno e medieval: o caso de estruturas de sujeito composto. In: GROBE, S.; ZIMMERMANN, K. (Eds.). O português brasileiro: pesquisas e projetos. Frankfurt am Main: TFM, 2000. p. 167-188. NASCIMENTO J. C. As narrativas (auto)biográficas como espaço/tempo de formação do professor alfabetizador. Disponível em: <http://www.alb.com.br/ anais16/sem10pdf/sm10ss01_02.pdf>. Acesso em: 10 jan. 2110.

OAKESHOTT, M. Learning and teaching. In: OAKESHOTT, M. The concept of education. London: Routledge, 1968.

PINKER, S. Do que é feito o pensamento: a língua como janela para a natureza humana. São Paulo: Companhia das Letras, 2008. 
SCHERRE, M. M. P. Doa-se lindos filhotes de poodle: variação linguística, mídia e preconceito. São Paulo: Parábola, 2005.

SCHERRE, M. M. P.; NARO, A. J. Sobre a concordância de número no português falado do Brasil. In RUFFINO, G. (Org.). Dialettologia, geolinguistica, sociolinguistica. (Atti del XXI Congresso Internazionale di Linguistica e Filologia Romanza) Centro di Studi Filologici e Linguistici Siciliani, Universitá di Palermo. Tübingen: Max Niemeyer Verlag, 1998. v. 5. p. 509- 523.

SCLIAR-CABRAL, L. Riquezas e dilemas da psicolinguística, exemplificados em pesquisa sobre narratividade. Boletim da Abralin, v. 3, p. 150-168, 1982.

SCLIAR-CABRAL, L. Narratividade em crianças e os processos de leitura. Florianópolis: UFSC, 1983.

SCLIAR-CABRAL, L. Caracterização das qualidades de narrativas em préescolares. Ilha do Desterro, v. 5, p. 56-74, 1984.

SCLIAR-CABRAL, Leonor. Emergence of Persons of Discourse. In: AILA CONGRESS, Singapura, 2002. Inédito.

SCLIAR-CABRAL, L. Princípios do sistema alfabético do português brasileiro. São Paulo: Contexto, 2003.

SCLIAR-CABRAL, L. Reconto de conto de fadas: recursos estilísticos. Linguistic and Literary Studies Journal, 2011. No prelo.

SCLIAR-CABRAL, L.; MACQUINNEY, B. Aquisição da morfologia verbal do PB. In: CONGRESO INTERNACIONAL ALFAL, 14., 2005, Monterrey. Memorias. Monterrey: ALFAL/Universidad Autónoma de Nuevo León, 2005. p. 80-89.

SOARES, M. E. A aquisição da competência textual: estratégias para a instauração da coerência textual. In: CABRAL, L. G.; MORAIS, J. Investigando a linguagem: ensaios em homenagem a Leonor Scliar-Cabral. Florianópolis: Mulheres, 1999. p. 227-244.

Recebido em 10/11/2012. Aprovado em 28/3/2012. 